\title{
Molecular dynamic investigation of size-dependent surface energy of icosahedral copper nanoparticles at different temperature
}

\author{
V.S. Myasnichenko ${ }^{1,2, \dagger}$, M. Razavi ${ }^{3}$, M. Outokesh ${ }^{3}$, N.Yu. Sdobnyakov ${ }^{1}$, M.D. Starostenkov ${ }^{2}$ \\ †virtson@gmail.com
}

\author{
${ }^{1}$ Tver State University, Zheliabova 33, 170100, Tver, Russia \\ ${ }^{2}$ Altai State Technical University, Lenina 46, 656038, Barnaul, Russia \\ ${ }^{3}$ Sharif University of Technology, Azadi Ave. 11365-11155, Tehran, Iran
}

\begin{abstract}
The study of the surface free energy (SFE) of metal at nanoscale is far from perfection and the obtained results are approach dependent. Despite the extensive investigations, there is still a lack of a complete model for the surface energy of metallic nanoparticles which could be able to consider effects of the particle size and shape. Most studies emphasize the size dependence of the melting characteristics, rather than considering the lattice deformation and the surface energy of nanoclusters. This research aimed at computation of SFE of copper nanoclusters depending on temperature over a wide range of sizes, containing 147 to 10179 atoms. We employed molecular dynamics simulation by using the embedded atom model and tightbinding Cleri-Rosato potential. Calculations were carried out on icosahedral Cu nanocluster with full-closed surface. This is the most stable shape in our range of sizes. Results of two series of computer experiments, made using the two interatomic potentials in LAMMPS program and our own software, were found to be in good accordance between themselfs. It was established that surface free energy decreases with increasing of cluster size, but grows with elevating of the temperature. Distribution of potential energy upon the inner and surface atoms of particles of various sizes has been performed. It was also revealed that for larger nanoclusters SFE is more sensitive to variation of temperature than one in case of small nanoparticles. The obtained result are very relevant for understanding and manipulating the desired properties of copper nanoparticles in industrial applications.
\end{abstract}

Keywords: surface energy, size effect, molecular dynamics, metal nanoparticle.

\section{Молекулярно-динамическое исследование размерно- зависимой поверхностной энергии икосаэдрических наночастиц меди при различной температуре}

\author{
Мясниченко В.С. ${ }^{1,2, \dagger}$, Разави M. ${ }^{3}$, Оутокеш M. ${ }^{3}$, Сдобняков Н.Ю. ${ }^{1}$, Старостенков М.Д. ${ }^{2}$ \\ †virtson@gmail.com
}

\author{
${ }^{1}$ Тверской государственный университет, Желябова 33, 170100, г. Тверь, Россия \\ ${ }^{2}$ Алтайский государственный технический университет, Ленина 46, 656038, г. Барнаул, Россия \\ ${ }^{3}$ Технологический университет им. Шарифа, Азади авеню, 11365-11155, Тегеран, Иран
}

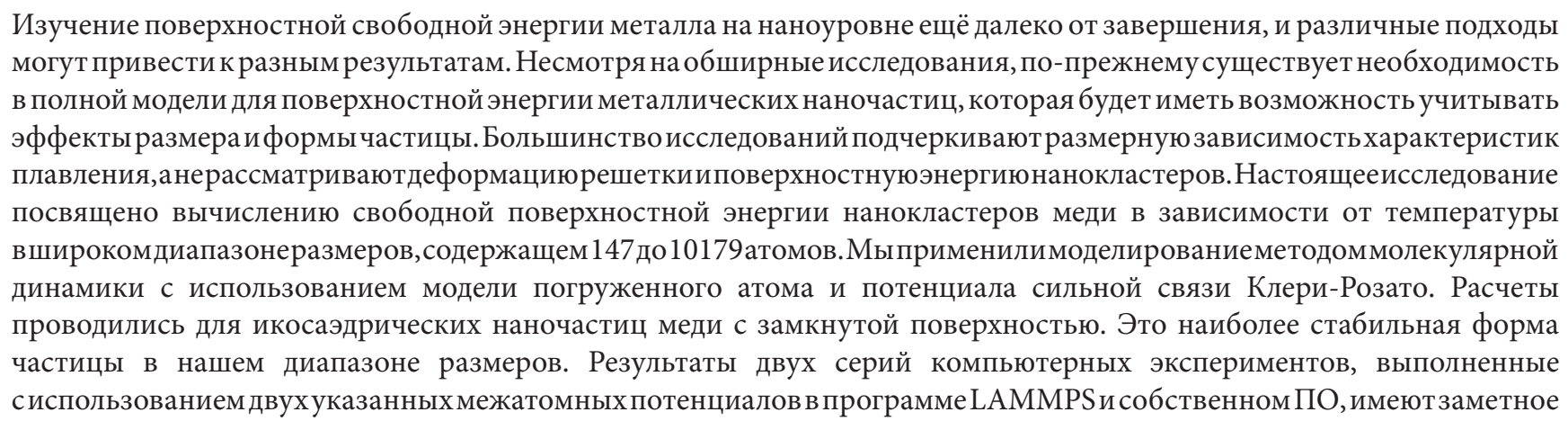


согласие между собой. Результаты показали, что свободная поверхностная энергия уменьшается с увеличением размера наночастицы, но возрастает сувеличением температуры. Проиллюстрировано распределениепотенциальной энергии по внутренним и поверхностным атомам частиц различного размера. Кроме того, было установлено, что свободная поверхностная энергия для больших наночастиц более чувствительна к изменению температуры, чем мелких нанокластеров. Эти результаты, как представляется, имеют первостепенное значение для понимания и манипулирования желаемыми свойствами наночастиц меди при промышленном применении.

Ключевые слова: поверхностная энергия, размерный эффект, молекулярная динамика, наночастица металла.

\section{Introduction}

Copper is the third most widely used metal after iron and aluminum. It has a great industrial significance as an electrical conductor and alloys constituent. Progress of nanotechnology, on the other hand, has opened new opportunities to copper applications. Copper nanoparticles (NPs), are now, under rigorous investigation as a catalyst, conductive paste, lubricant and sintering additives, and in optical [1-2] and biological researches [3-4]. Indeed, whenever possible, $\mathrm{Cu}$ NPs are used as an inexpensive alternative to silver and other precious metal nanoparticles.

Many of the practically-important properties of metallic NPs such as catalytic activity, melting temperature, crystal growth, and surface faceting, are influenced by their surface free energy (SFE) level [5]. This is because, the surfaceto-volume ratio of the particles greatly increases as their sizes decrease to a few nanometer. It is well known that the properties of surface atoms differ from those of the bulk, as a result of the reduced interaction with neighboring atoms i.e. the lower coordination number [6].

From the thermodynamics point of view, SFE is defined as the reversible work per units area required for creating a new surface at the constant temperature, volume, and total number of atoms [7]. A full and consistent thermodynamic description of surface energy, its relation with surface tension, and differential equations describing its size dependency is given in Rusanov's works [8-9].

When considering the surface phenomena in micro- and nanometric levels, the widely used concept of capillary effects of the second kind, proposed by L. Shcherbakov is highly valuable [10]. This approach is taken to find the excess free energy of the NPs, when are compared to their macroscopic counterpart, with the same number of atoms and similar external parameters (i.e. temperature and pressure). Here, the word "excess" refers [10] to the area of equimolecular dividing surfaces and thus is determined by the effective specific surface free energy of small particles. Note that the problem of applicability of the Gibbs thermodynamic relations to the nanosized objects has been already addressed by Samsonov et al [11]. Therefore, surface energy is the important physical quantity of nanocrystals, especially for nanoscaled devices, because, with decreasing the size of the devices, the ratio of surface/volume will increase, and then the surface energy will greatly affect the properties of materials.

The surface energy of metal nanoparticles has been extensively investigated, both as theoretically and experimentally $[12-14]$, and it has been reported that surface free energy depends on the particle size, especially in the range of below $10 \mathrm{~nm}$ [15]. For instance, Ouyang et al [16] studied the components of the surface energy from the viewpoint of thermodynamics and quantum mechanics, and they found that the surface energy decreases with decreasing of the size of nanocrystals. Nanda et al [7] in their study on size-dependent evaporation of nanoparticles obtained a constant surface energy of $7.2 \mathrm{~J} / \mathrm{m}^{2}$ for $\mathrm{Ag}$ nanoparticles, which is higher than the bulk value. Medasani et al [17] applied density functional theory (DFT) and the computational semi-empirical Embedded Atom Method (EAM) to calculate surface energies and stresses of the Ag nanoclusters with $0.5-5.5 \mathrm{~nm}$ diameter, and according to them, surface energy increased with decreasing of the size.

Apparently, the study of the surface free energy at nanoscale is far from consummation, different approaches may lead to the different results. Indeed, despite the abovementioned extensive investigation, there is still a need for a complete model of the surface energy of the metallic NPs that can accounts for its dependency on the particle sizes.

The current study was aimed at calculation of the surface free energy of copper NPs, as a function of size, and temperature. The most stable geometrical shapes of $\mathrm{Cu}$ NPs in our range of sizes, up to 10179 atoms, are: icosahedron, decahedron and cuboctahedron, in the decreasing order of stability [18-20]. But, in order to avoid the excessive discussions, we limited ourselves, on the most stable type of structure.

\section{Simulation methods}

In the current study we employed molecular dynamics simulation (MD) to investigate the effects of size and temperature on the SFE of the icosahedral $\mathrm{Cu}$ nanoclusters.

We employed the many-body EAM potential [21] as implemented in the LAMMPS code [22-23] to describe the interatomic interactions. Also we used tight-binding (TB) potential developed by Cleri and Rosato [24] and implemented in our own-developed molecular-dynamic software ClusterEvolution [25]. Both potentials were previously used to describe the behaviors of surface energy and other properties of transition fcc metals in bulk form, mono- and bimetallic nanoparticles [17, 26-28].

We considered 12 icosahedral copper NPs of different sizes (containing $N=147,309,561,923,1415,2057,2869$, 3871, 5083, 6525, 8217 and 10179 atoms). Each nanoparticle had a full-closed surface consisting of 20 tightly packed triangular faces, corresponding to $\{111\}$ face of the crystal lattice.

The FCC-metal and rare-gas clusters with these atomic numbers $(N=13,55,147,309 \ldots)$ are so-called the magic clusters, which show an increased stability relative to nonmagic clusters. The known expression for the cluster size $N$ of the 'magic' serial is: 


$$
N(k)=\frac{1}{3}\left(10 k^{3}+15 k^{2}+11 k+3\right) .
$$

From eq. (1) we get the expression for the number of surface atoms Nsurf:

$$
N_{\text {surf }}(k)=N(k)-N(k-1)=10 k^{2}+2 .
$$

The specific surface energy per unit area, is calculated as $[13,28]$ :

$$
E_{\text {surf }}=\frac{E_{\text {pot, cluster }}-E_{\text {pot, bulk }}}{A_{\text {cluster }}},
$$

where $E_{\text {pot,cluster }}$ is the potential energy of the cluster, $E_{\text {bull,cluster }}$ is the potential energy of a bulk system containing the same number of atoms, and $A_{\text {cluster }}$ is the total cluster surface area. To calculate the surface energy at $0 \mathrm{~K}$, we minimized the structure using the conjugate gradient minimization method [29].

For calculation of the surface energy at non-zero temperatures, $\mathrm{MD}$ simulations were carried out in the canonical ensemble. The temperature in LAMMPS was controlled by employing the Nose - Hoover thermostat [30 - 31]. In all calculations, the time step was set at $0.9 \mathrm{fs}$.

Each system was equilibrated for 100 ps prior to analysis. The surface energies at finite temperatures were calculated based on average potential energies and cluster surface areas, averaging over the 3 ps using eq. (3). Molecular dynamics simulations of bulk copper structure were carried out by using the periodic boundary conditions in three dimensions for block of 5000 atoms. In the case of nanoclusters, simulations were carried out without periodic boundary conditions.

Nanoparticle surface areas were calculated using the qhull code [32-33]. The structural evolution of clusters during the melting process and symmetry in the immediate environment of each atom was analyzed by means of the common neighbors analysis method [34].

\section{Results and discussion}

The surface of an icosahedron consists of $\{111\}$ facets. We calculated the surface energy of this facet type for an infinite surface area. With use of TB potential we found a value of $1.31 \mathrm{~J} / \mathrm{m}^{2}$ for the SFE of $\{111\}$ facet, which is in a good agreement with the $1.41 \mathrm{~J} / \mathrm{m}^{2}$, reported in ref. [26].

The caloric curves were calculated for all cluster size. In Fig. 1 we show the results for clusters Cu147 and Cu923. A sharp increase in energy that can be seen at $950 \mathrm{~K}$ and $1000 \mathrm{~K}$ for the smaller and larger clusters, respectively which is typical for signaling the onset of the melting of the clusters.

The calculated potential energy per atom and the cluster's surface energy for the copper nanoparticles as a function of size at $0.01 \mathrm{~K}$ are shown in Fig. 2. The potential energy values are almost the same for the two used potentials, for big size clusters. Fig. 3 shows the distribution of potential energy (TB potential) in some selected clusters. The Ovito [35] software package is used for visualization.

Abdul-Hafidh et al. in their study [36] showed that surface free energy is sensitive to the shape, size and structure of the nanosolids. The SFE was found to decrease with size

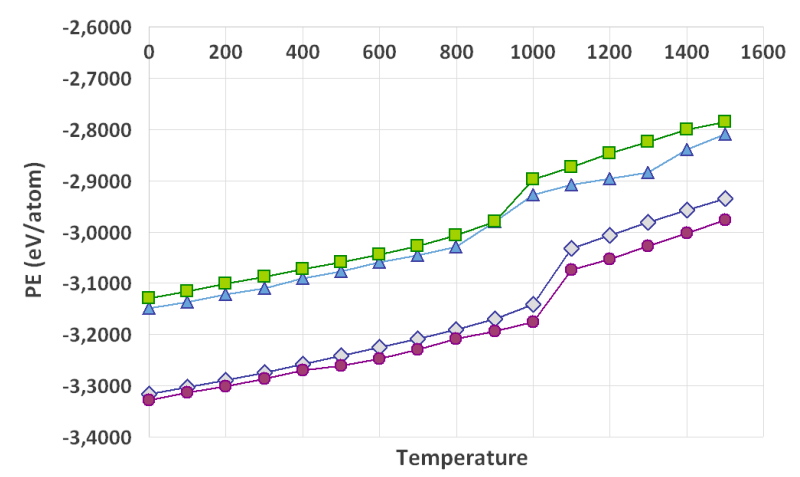

Fig. 1. Potential energy curves for the icosahedral nanoparticles Cu147 (EAM - triangles, TB - squares) and Cu923 (EAM circles, $\mathrm{TB}$ - rhombus) as a function of temperature.

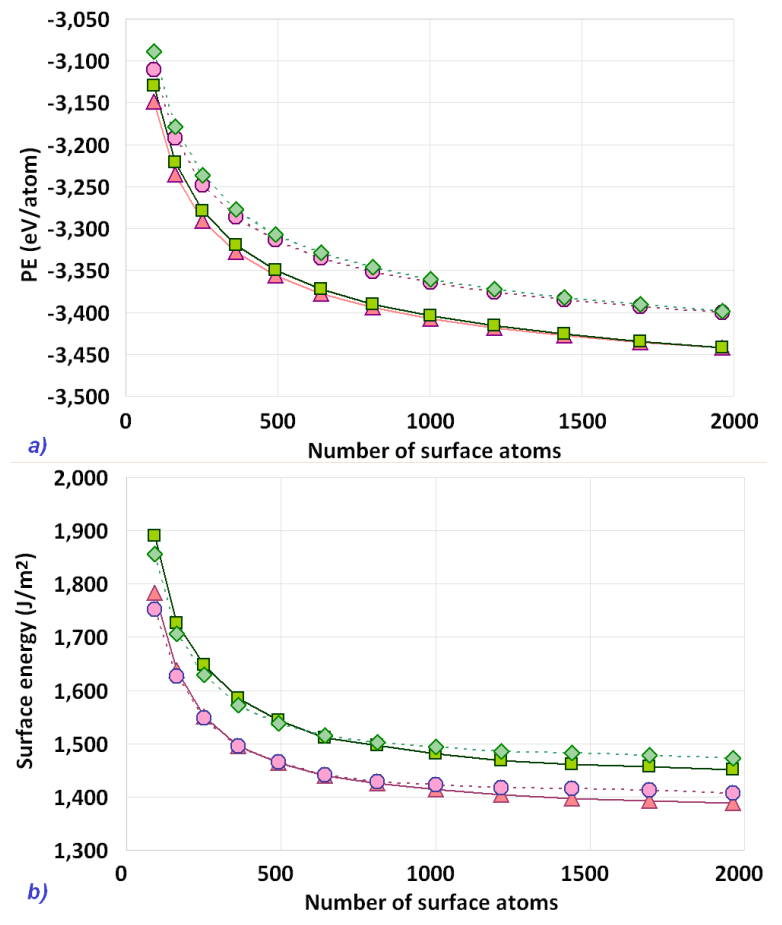

Fig. 2. Calculated potential energy per atom (a) and surface energy (b) for $\mathrm{Cu}$ nanoparticles as a function of $N_{\text {surf }}$ at different temperature, within EAM potential ( $0.01 \mathrm{~K}$ - triangles, $300 \mathrm{~K}$ - circles) and TB potential $(0.01 \mathrm{~K}$ - squares, $300 \mathrm{~K}-$ rhombus).

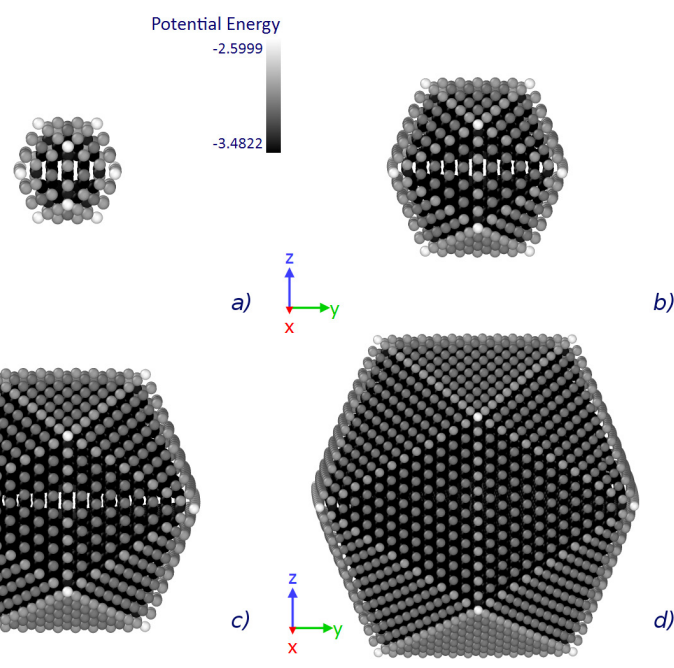

Fig.3.Distribution of potential energy per atom $(\mathrm{eV})$ in the icosahedral $\mathrm{Cu}$ clusters of different sizes. Atoms shown with scale $60 \%$. 
for small spherical NPs, while this trend was completely reversed (to increase) as the shape of the NPs was appreciably deformed from the sphere. It can be seen in Fig. $2 b$ that the surface energy at $0.01 \mathrm{~K}$ decreases with increasing of the cluster size; though, with formation the further growth of the nanocluster, SFE asymptotically approaches to the bulk value for the $\{111\}$ facets.

The surface area of copper clusters, calculated by averaging of both potentials, monotonically increases with the number of surface atoms, and also increases when heated due to the thermal expansion. Fig. 4 shows surface-to-volume ratio of $\mathrm{Cu}$ icosahedron as a function of size.

Due to the effects of thermal expansion and thermal disorder, the surface energy of nanoparticles are also depends on temperature. Fig. 5 shows the calculated temperature dependence of the surface energy of icosahedral copper nanoclusters comprising 147, 923 and 2869 atoms at different temperatures up to $1400 \mathrm{~K}$. As we can see, the SFE size dependence does not change monotonically: it has a region of a small decline of energy, before the start of structural changes due to surface melting, and it grows for particles in liquid state.

The figures 1, 2 and 5 show a notable agreement between the numerical values of the two series of SFE simulations namely: LAMMPS + EAM and ClusterEvolution + TB. The calculations demonstrate that small nanoparticles $(N=147$ atoms) melt at temperatures $100-150 \mathrm{~K}$ lower than the larger nanoparticles, as is clearly seen in Fig. 5. The observed melting trends are similar to earlier reports for $\mathrm{Cu}$ nanoparticles [37] and SFE trends are similar to reported for Au clusters in ref. [26]. For larger clusters, we observe an appreciable increase in the surface energy with increasing temperature, which is greater than those observed for smaller clusters (Fig. 5).

Our results, to some extent, comply with the results obtained by the thermodynamic perturbation theory [11]. In ref. 11 authors claimed that the averaged specific surface free energy (the averaged surface tension) of the crystals strongly depends on the choice of the equimolecular dividing surface position. It is interesting to note that for an ideally faced fcc nanocrystals, the averaged specific surface free energy can increase with decreasing the size. This is also due to the fact that as size of a nanocluster decreases, its surface to volume ratio increases, and thus the specific surface energy of the smaller nanoclusters increases accordingly. Typical potential energy curves are also calculated, demonstrating the Gibbs Thomson effect (depression of the freezing point).

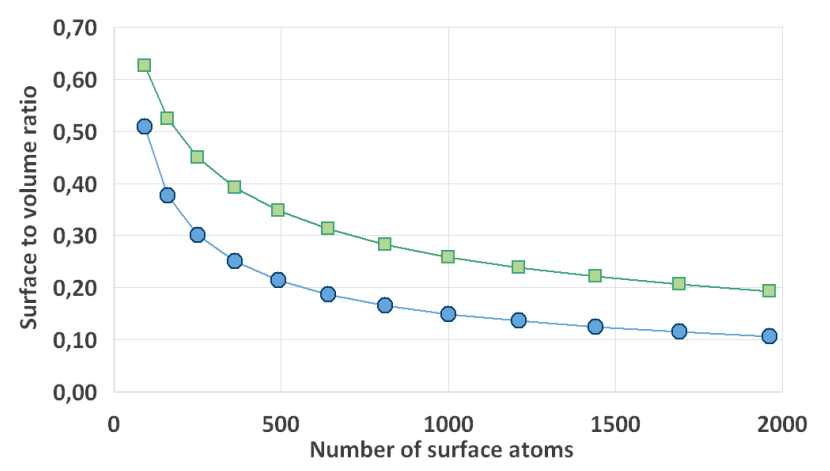

Fig. 4. Surface to volume ratio ( $1 / \AA$, circles) and $N_{\text {surf }} / N$ ratio (squares) vs. number of surface atoms $N_{\text {surf }}$ for icosahedral $\mathrm{Cu}$ nanoparticles at $0.01 \mathrm{~K}$.

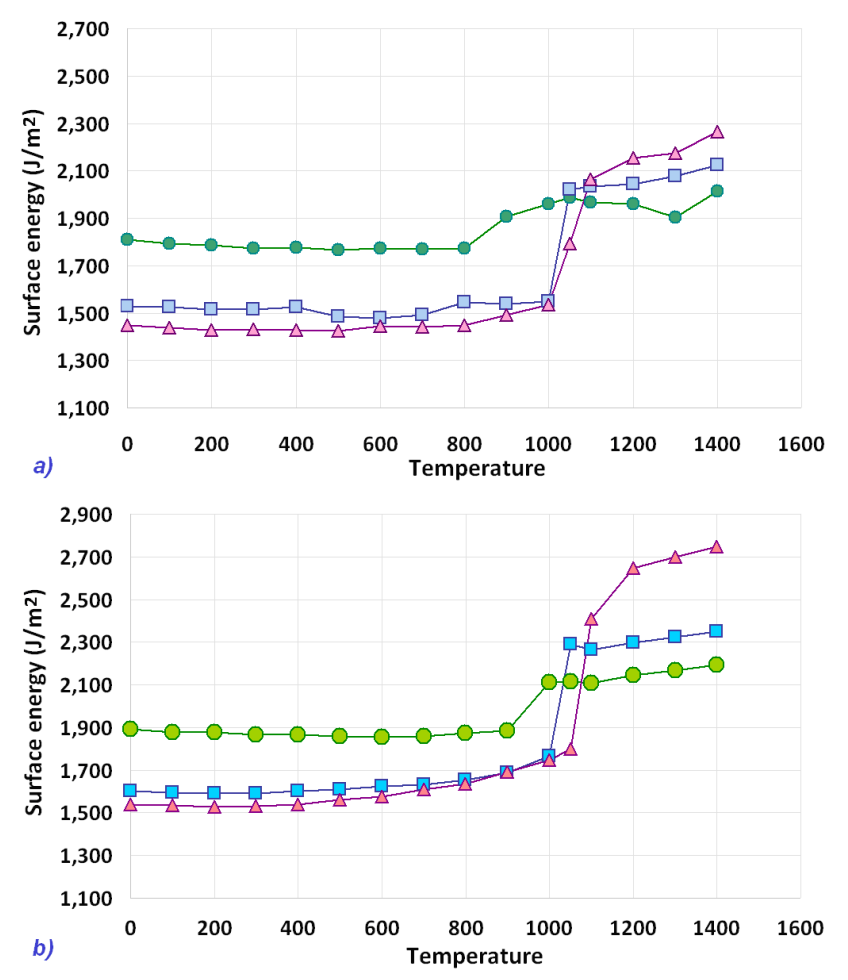

Fig. 5. A comparison of surface energies with use of (a) EAM interatomic potential and (b) TB potential for the icosahedral nanoparticles Cu147 (circles), Cu923 (squares) and Cu2869 (triangles) in the temperature range $0-1400 \mathrm{~K}$.

Acknowledgements. This study was partially supported by RFBR, project No 16-33-00742 mol_a, the Ministry of Educationand Science of the Russian Federation within the framework of the fulfillment of state works in the sphere of scientific activity (project no. 3.2448.2014/K), and by Dept. of Energy Engineering of Sharif University of Technology, Iran.

\section{References}

1. Shen Ping et al. J. Phys. Chem. C. 120 (16), 8900-8906 (2016).

2. A. V. Kalenskii, A. A. Zvekov, A. P. Nikitin, M. V. Anan'eva. Russian Physics Journal. 58 (8), 1098 (2015).

3. S. Chowdhury, V.R. Bhethanabotla, R.Sen. Appl. Phys. Lett. 95 (13), 131115 (2009).

4. W. Li, F. Chen. J. Nanopart. Res. 15 (7), 1809 (2013).

5. F. Bechstedt. Principles of surface physics. 4th ed. New York: Springer, (2003) 342 p.

6. K. Nanda, et al. Phys. Rev. Lett. 91 (10), 106102 (2003).

7. R. Dingreville, J. Qu, C. Mohammed. J. Mech. Phys. Solids. 53 (8), 1827 (2005).

8. A.I. Rusanov. Thermodynamics of surface phenomena [in Russian], Leningrad: Izd. LGU, (1960) 181 p.

9. A. I. Rusanov. Surf. Sci. Rep. 37 (25), 111 (2003).

10. L.M. Shcherbakov. General theory of capillary effects of the second type. in: Research in the Field of Surface Forces [in Russian], Moscow.: Izd. Akad. Nauk SSSR, (1961), pp. $28-37$.

11. V.M. Samsonov, N.Yu. Sdobnyakov, A.N. Bazulev. Colloids and Surf. A. 239, 113 (2004) 
12. J.-M. Zhang, F. Ma, K.-W.Xu. Appl. Surf. Sci. 229 (1), 34 (2004).

13. E. Aghemenloh, et al. Comput. Mater. Sci. 50 (12), 3290 (2011).

14. X. Wang, et al. Surface Science. 551 (3), 179 (2004).

15. R. Shuttleworth. Proc. Phys. Soc. A. 63 (5), 444 (1950).

16. G. Ouyang, X. Tan, G. Yang. Phys. Rev. B. 74 (19), 195408 (2006).

17. B. Medasani, Y.H. Park, I. Vasiliev. Phys. Rev. B. 75 (23), 235436 (2007).

18. M. Kabir, A. Mookerjee, A. Bhattacharya. Phys. Rev. A. 69 (4), 043203 (2004).

19. V.S. Myasnichenko, M.D. Starostenkov, Appl. Surf. Sci. 260, 51 (2012).

20. V.S. Myasnichenko, P.M. Ershov, N.Yu. Sdobnyakov, D.N. Sokolov. Physical and chemical aspects of the study of clusters, nanostructures and nanomaterials: Interuniver. coll. proceed. 7, 378 (2015) [in Russian].

21. M. S. Daw, M. I. Baskes. Phys. Rev. B. 29 (12), 6443 (1984).

22. S. Plimpton. J. Comp. Phys. 117 (1), 1 (1995).

23. Large-scale Atomic/Molecular Massively Parallel Simulator. Available online from: http://lammps.sandia.gov

24. F. Cleri and V. Rosato. Phys. Rev. B: Condens. Matter Mater. Phys., 48 (1), 22 (1993).
25. V.S. Myasnichenko. ClusterEvolution. Certificate of Russian state registration of the computer program № 2011615692 . July 20, 2011.

26. J.-M. Zhang, F. Ma, K.-W.Xu. Appl. Surf. Sci. 229 (1-4) 34 (2004).

27. F. Taherkhani, H. Akbarzadeh, H. Rezania. J. Alloys Compd. 617, 746 (2014).

28. S. Ali, V.S. Myasnichenko, E.C. Neyts. Phys. Chem. Chem. Phys. 18, 792 (2016).

29. I. Stich, R. Car, M. Parrinello and S. Baroni. Phys. Rev. B. 39 (8), 4997 (1989).

30. S. Nose. J. Chem. Phys. 81 (1), 511 (1984).

31. W. G. Hoover. Phys. Rev. A. 31 (3), 1695 (1985).

32. C.B. Barber, D.P. Dobkin and H. Huhdanpaa. ACM Trans. on Mathematical Software, 22 (4), 469 (1996).

33. Qhull: computational code for calculating surface area, volume etc. Available online from: http://www.qhull.org.

34. J. D. Honeycut, H. C. Andersen. J. Phys. Chem. 91, 4950 (1987).

35. A. Stukowski. Modell. Simul. Mater. Sci. Eng. 18, 015012 (2010).

36. E. H. Abdul-Hafidh, B. Aïssa. Appl. Surf. Sci. 379, 411 (2016).

37. L. Wang, Y. Zhang, X. Bian, Y. Chen. Phys. Lett. A. 310, 197 (2003). 